\title{
Advances in Vasodilatory Shock: A Concise Review
}

\author{
Sandeep Lahiry ${ }^{1}$, Sayanta Thakur ${ }^{2}$, Dwaipayan S Chakraborty ${ }^{3}$
}

\begin{abstract}
Vasodilatory shock is a critical manifestation of cardiovascular failure. There is uncontrolled vasodilation and vascular hyporesponsiveness to endogenous vasoconstrictors, causing the failure of physiologic vasoregulatory mechanisms. Unfortunately, only few randomized studies exist to guide clinical management and hemodynamic stabilization in patients who do not respond to the standard approach of managing vasodilatory shock. The present review offers the latest updates in management of this important clinical entity and a guidance framework for future research. Keywords: Hypotension, Sepsis, Shock, Vasodilatory shock

Indian Journal of Critical Care Medicine (2019): 10.5005/jp-journals-10071-23266
\end{abstract}

\section{INTRODUCTION}

Shock, a common clinical manifestation of circulatory compromise, results in decreased delivery of oxygenated blood to tissues culminating in decreased organ perfusion as well as cellular dysfunction. Table 1 provides an overview of different types of shock. Approximately one-third of patients in the intensive care unit (ICU) can be diagnosed harboring the clinical condition, ${ }^{1}$ which can broadly be classified into four categories:

1. Hypovolemic shock (due to external or internal fluid loss, such as hemorrhage)

2. Cardiogenic shock (due to acute myocardial infarction, cardiomyopathy, arrhythmias, and valvular heart diseases)

3. Obstructive type of shock (due to cardiac tamponade and pulmonary embolism), and

4. Vasodilatory shock (due to sepsis or anaphylaxis).

Septic shock, a form of vasodilatory shock, is the most common form of shock in critically ill patients, followed by cardiogenic and hypovolemic shocks. ${ }^{1}$ In most other subtypes, there is inadequate oxygen transport attributed to low-cardiac output. However, in vasodilatory shock, clinical manifestation ensues due to decreased systemic vascular resistance (SVR) with alteration in oxygen delivery to cells.
${ }^{1-3}$ Department of Pharmacology, Institute of Postgraduate Medical Education and Research, Kolkata, West Bengal, India

Corresponding Author: Sandeep Lahiry, Department of Pharmacology, Institute of Postgraduate Medical Education and Research, Kolkata, West Bengal, India, e-mail: sndplry@gmail.com

How to cite this article: Lahiry S, Thakur S, Chakraborty DS. Advances in Vasodilatory Shock: A Concise Review. Indian J Crit Care Med 2019;23(10):475-480.

Source of support: Nil

Conflict of interest: None

\section{Vasodilatory Shock and Sepsis}

Sepsis is the most common cause of vasodilatory shock affecting more than 1.5 million Americans each year at an annual burden of cost of more than $\$ 20$ billion. $^{2}$ Sepsis is also a significant challenge in India in context of the healthcare facility, health education and awareness, and limitation in resource. The findings of mortality from sepsis have been diverge in different age groups, ranging from as low as $9 \%$ in neonates to as high as $63 \%$ in the elderly. ${ }^{3}$ One study raised definite apprehension indicating that $25 \%$ of the total patients admitted in ICU developed severe sepsis or

Table 1: Overview of different types of shock

\begin{tabular}{|c|c|c|c|}
\hline \multicolumn{4}{|c|}{$\begin{array}{c}\text { Shock } \\
\text { (Hypotension + decreased tissue perfusion and oxygenation) }\end{array}$} \\
\hline Low CO + fluid responsiveness & Low CO (+) fluid responsiveness & Low CO (+) fluid responsiveness & High CO (+) fluid responsiveness \\
\hline Hypovolemic shock & Cardiogenic shock & Obstructive shock & Vasodilatory shock \\
\hline $\begin{array}{l}\text { Hemorrhage excessive diuresis } \\
\text { "Third-spacing" under-resuscitated } \\
\text { sepsis }\end{array}$ & $\begin{array}{l}\text { Myocardial compromise, e.g., AMI, } \\
\text { stress cardiomyopathy }\end{array}$ & $\begin{array}{l}\text { Cardiac tamponade, tension } \\
\text { pneumothorax, pulmonary } \\
\text { embolism, dynamic hyperinflation }\end{array}$ & $\begin{array}{l}\text { Sepsis } \\
\text { Anaphylactic shock } \\
\text { Drugs: Propofol, vasodilators } \\
\text { Metabolic acidosis } \\
\text { Hypocalcemia }\end{array}$ \\
\hline $\begin{array}{l}\text { - Blood diagnostics } \\
\text { - Imaging to identify suspected } \\
\text { bleeding sites } \\
\text { - Cardiac filling pressure } \\
\text { - Fluid challenge } \\
\text { - Blood transfusion, if bleeding }\end{array}$ & $\begin{array}{l}\text { - Imaging: echo, PAC } \\
\text { - Consider inotropes } \\
\text { - Consider MV support }\end{array}$ & $\begin{array}{l}\text { - Imaging: Chest radiograph, } \\
\text { echo, pleural USG } \\
\text { - Bladder pressure } \\
\text { - MV waveforms } \\
\text { - Fluid challenge = correction of } \\
\text { underlying cause }\end{array}$ & $\begin{array}{l}\text { - Diagnostics: Blood cultures, } \\
\text { procalcitonin, ionized calcium, } \\
\text { ABG, lactate } \\
\text { - Discontinue offending } \\
\text { medications } \\
\text { - Increase vasopressors }\end{array}$ \\
\hline
\end{tabular}

ABG, arterial blood gas; $\mathrm{AMI}$, acute myocardial infarction; $\mathrm{CO}$, cardiac output; echo, echocardiography; MV, mechanical ventilation; PAC, pulmonary artery catheter; USG, ultrasonogram

() The Author(s). 2019 Open Access This article is distributed under the terms of the Creative Commons Attribution 4.0 International License (https://creativecommons. org/licenses/by-nc/4.0/), which permits unrestricted use, distribution, and non-commercial reproduction in any medium, provided you give appropriate credit to the original author(s) and the source, provide a link to the Creative Commons license, and indicate if changes were made. The Creative Commons Public Domain Dedication waiver (http://creativecommons.org/publicdomain/zero/1.0/) applies to the data made available in this article, unless otherwise stated. 
septic shock with an estimated mortality $>50 \% .{ }^{4}$ The surge in the death toll of sepsis is representative of the overall burden of the hospital-acquired infection (HAI) in the country. Paucity in resource is a further hindrance over the propagation of sepsis research infrastructure throughout the country. In this regard, an example of the initiation of research infrastructure was promulgated by Indian Society of Critical Care Medicine by developing a "cloud-based database" called "Customized Health in Intensive Care, Trainable Research and Analysis" (CHITRA) (http://www.isccm.org/chitra. aspx). ${ }^{5}$

\section{Pathophysiology}

The pathophysiology of vasodilatory shock could range from multiple contributory states, including systemic inflammatory response syndrome (SIRS), anaphylaxis, pancreatitis, hepatic failure, neurologic shock due to spinal cord injury, glucocorticoid deficiency, and various toxins. Vasodilatory shock can occur solely or in combination with all other types of shocks. Put simply, vasodilatory shock can be the final common pathway for severe shock of any cause (Flowchart 1). ${ }^{6}$

In all the forms of vasodilatory shock, plasma catecholamine concentrations are markedly increased, and the renin-angiotensin system (RAS) gets activated. However, vasodilation and hypotension results in less oxygen being supplied to the peripheral tissues. The three cardinal mechanisms underpinning the pathologic state are the following:

1. Activation of adenosine triphosphate (ATP)-sensitive potassium channels ( $\mathrm{K}^{+}$-ATP channels) in the plasma membrane of vascular smooth muscle.

2. Activation of the inducible form of nitric oxide (NO) synthase, and

3. Deficiency of the hormone vasopressin.
$\mathrm{K}^{+}$-ATP channels are physiologically activated by decreases in the cellular ATP concentration and by increases in cellular concentrations of hydrogen ion and lactate. The opening of $\mathrm{K}^{+}$-ATP channels allows an efflux of potassium and, thus, hyperpolarizing the plasma membrane. This causes closer of voltage-gated calcium channels with subsequent vasodilation.

NO production is increased due to the expression of the "inducible form" of NO synthase in many types of cells, including vascular smooth muscle cells and endothelium. Involvement of several cytokines (e.g., interleukin-1 $\beta$, interleukin-6, tumor necrosis factor- $\alpha$, interferon- $\gamma$, and adenosine) is predicted, as the mechanism is not well established.

In response to hypotension, such as that due to hemorrhage or sepsis, vasopressin releases from the neurohypophysis, and its concentration in plasma markedly increases, which contributes to the maintenance of arterial pressure. As shock worsens, the initially very high concentrations of vasopressin in plasma decrease. The exact mechanism responsible for these low concentrations remains to be determined, but it is known that neurohypophyseal stores of vasopressin may be depleted after profound osmotic stimulation.

\section{Hemodynamic Changes}

Hemodynamically in any kind of vasodilatory shock, initially cardiac output and heart rate are increased to compensate of reduced oxygen supply to tissues. There is also hyperdynamic left ventricular systolic contraction to propel blood to tissues. Despite the inotropic and chronotropic stimulation, SVR decreases due to vasodilatation. This results in increase in venous capacitance and pooling of blood in the venous system, prompting a dip in cardiac output. As a sequel, various counterregulatory systems, such as the sympathetic nervous system, the renin-angiotensin-aldosterone system gets activated to counterbalance the state. But typically, SVR and preload

Flowchart 1: Pathophysiology of vasodilatory shock

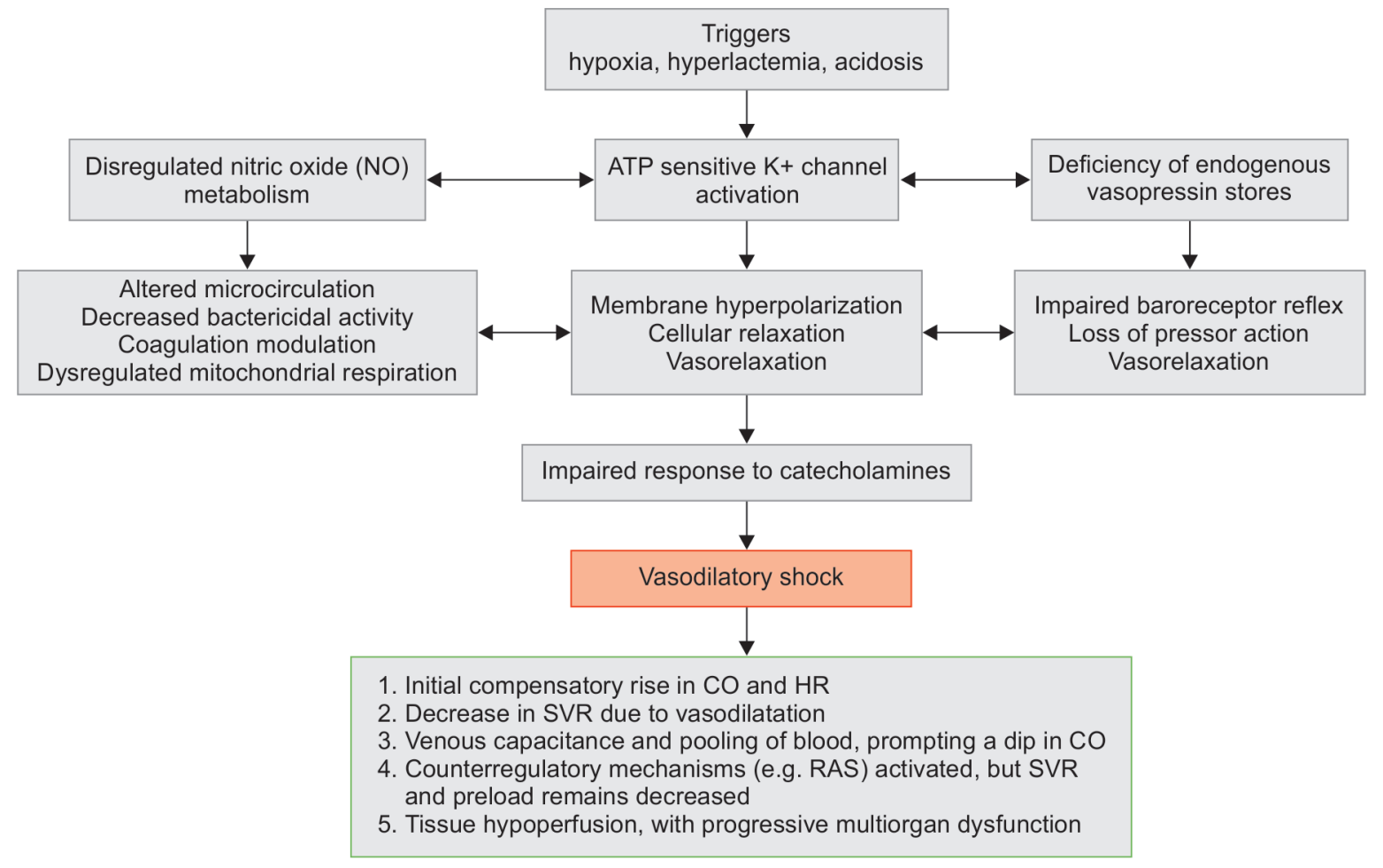


remain decreased. Therefore, compromised tissue oxygenation in the context of adequate or even increased cardiac output can be a characteristic feature of typical vasodilatory shock (Flowchart 1). ${ }^{6}$

When sepsis-induced hypotension remains refractory to initial management with fluid resuscitation, septic shock ensues. Septic shock is distinguished from other shock states as a distributive type of shock. At an early "compensated" stage of shock, blood pressure is maintained with other signs of distributive shock, such as the patient being in a hyperdynamic state, which is the characteristic of septic shock. Clinically, patients have a dynamic precordium with tachycardia and bounding peripheral pulses, warm extremities, flash capillary refill ( $<1$ second), also known as "warm shock." This stage of shock can reverse if managed aggressively with fluid resuscitation and vasoactive support. ${ }^{7}$

As shock progresses into the uncompensated stage, hypotension set in with features such as cool extremities, delayed capillary refill (>3 seconds), and thread pulse. This state is typically known as "cold shock." This state could prompt continued tissue hypoperfusion leading to irreversible, progressive multiorgan dysfunction syndrome and death.

\section{Management}

\section{Objective}

The initial (and main) goal of the treatment is the reversal of underlying cause. For instance, in septic shock removal of focus of infection can dramatically improve survival followed by hemodynamic stabilization with fluids and vasopressors.

\section{Initial Resuscitation}

The most common cause of vasodilatory shock is sepsis. It is recommended that the treatment and resuscitation begin immediately as this is a medical emergency. The following steps are necessary:

- At least $30 \mathrm{~mL} / \mathrm{kg}$ of intravenous (IV) crystalloid fluid be given within the first 3 hours.

- Following initial fluid resuscitation, additional fluids be guided by frequent reassessment of hemodynamic status. Reassessment should include a thorough clinical examination and the evaluation of heart rate, blood pressure, arterial oxygen saturation, respiratory rate, temperature, urine output, and others, as well as other noninvasive or invasive monitoring, as available.

- Further hemodynamic assessment (such as assessing cardiac function) to determine the type of shock if clinical examination does not lead to clear diagnosis. It is recommended to use dynamic variables, such as stroke volume (SV), pulse pressure variation (PPV), SV variation with passive leg raise or fluid challenge, compared with static variables, such as central venous pressure (CVP), to predict fluid responsiveness. ${ }^{8}$

- An initial target of mean arterial pressure (MAP) $\geq 65 \mathrm{~mm}$ $\mathrm{Hg}$ in patients with septic shock is recommended, which is irrespective of the vasopressors used. ${ }^{9}$

The Surviving Sepsis Campaign (SSC) bundles update in 2018 recommends that the 3-hour and 6-hour bundles should be combined into a single "hour-1 bundle" with the explicit intention of beginning resuscitation and management immediately. ${ }^{10}$ It is believed that this change could reflect the clinical reality at the bedside of these seriously ill patients with sepsis and septic shock. Elevated lactate levels can be used as a marker of tissue
Table 2: The Surviving Sepsis Campaign Bundles Update 2018: Elements with strength of recommendations and underpinning quality of evidence

\begin{tabular}{ll}
\hline Hour 1 - Bundle Element & $\begin{array}{l}\text { Grade of recommendation with } \\
\text { level of evidence }\end{array}$ \\
\hline $\begin{array}{l}\text { Measurement of lactate level; } \\
\text { remeasure if initial lactate is }>2\end{array}$ & $\begin{array}{l}\text { Weak recommendation, low } \\
\text { mmol/L }\end{array}$
\end{tabular}

$\mathrm{mmol} / \mathrm{L}$

Obtaining blood culture prior to Best practice statement administration of antibiotics

Using broad-spectrum antibiotics

Strong recommendation, moderate quality of evidence

Rapid administration of $30 \mathrm{~mL}$ Strong recommendation, low $\mathrm{kg}$ crystalloid for hypotension or quality of evidence lactate $\geq 4 \mathrm{mmol} / \mathrm{L}$

Apply vasopressor if patient is Strong recommendation, hypotensive during or after fluid moderate quality of evidence resuscitation to maintain MAP $\geq 65 \mathrm{~mm} \mathrm{Hg}$

(Source: http://www.survivingsepsis.org/SiteCollectionDocuments/Surviving-Sepsis-Campaign-Hour-1-Bundle-2018.pdf)

hypoperfusion. The recommendations with its applied grade and level of evidence are listed in Table 2.

\section{Fluid Therapy}

It is recommended to continue fluid challenge if hemodynamic factors continue to improve. Crystalloids are the fluid of choice for initial resuscitation and subsequent volume replacement in patients with septic shock, though balanced crystalloids or saline is recommended. The use of albumin is justified in addition to crystalloids for resuscitation and subsequent volume replacement if substantial amounts of crystalloids are needed. Recommendations are against using hydroxyethyl starches (HESs) for volume replacement. Crystalloids should be preferred over gelatins in resuscitating patients with sepsis/septic shock due to surge in the risk of anaphylaxis with accompanying adverse outcome, such as increasing mortality, renal failure, and bleeding possibly due to extravascular uptake and coagulation impairment. 9,11

In SAFE trial ( $n=6997$, multicenter, double blind, parallel group, randomized, controlled trial $[\mathrm{RCT}])$, there is no significant difference in survival between two groups ( $4 \%$ albumin vs normal saline) in initial ICU resuscitation. ${ }^{12}$ Similarly, in 2014 Albumin Italian Outcome Sepsis (ALBIOS) trial ( $n=1818$, multicenter, open-label, randomized trial), where patients received $20 \%$ albumin/crystalloid or crystalloid during resuscitation and through day 28 in the ICU, the albumin/ crystalloid group had statistically different hemodynamic profile than the crystalloid group with no increase in survival. ${ }^{13}$

\section{Vasoactive Medications}

Norepinephrine is recommended as the first-choice vasopressor. The addition of either vasopressin (up to $0.03 \mathrm{U} / \mathrm{min}$ ) or epinephrine to norepinephrine with the intent to raise MAP can be followed. Dopamine in low dose is preferred as an alternative vasopressor to norepinephrine only in highly selected patients (e.g., those with low risk of tachyarrhythmias and those with absolute or relative bradycardia). Dobutamine can also be used in patients who show evidence of persistent hypoperfusion despite adequate fluid loading and the use of vasopressor agents. ${ }^{9}$ 
Conflicting result is followed in subsequent trials of vasopressor agents:

- In dopamine vs norepinephrine trial (multicenter, open label, randomized, controlled trial), there was no significant difference in 28 days, 6 - or 12-month mortality. ${ }^{14}$

- In meta-analysis of 32 trials of vasopressors in septic shock, norepinephrine was favored over dopamine due to survival benefit, better hemodynamic profile, and less incidence of adverse event. $^{15}$

- In epinephrine vs norepinephrine trial ( $n=277$, multicenter, double-blind, parallel group, randomized, controlled trial), there was no difference in MAP achieved, max daily dose, mean CVP, or net fluid balance during infusion. ${ }^{16}$ But epinephrine was associated with significant development $(<0.001)$ of tachycardia and lactic acidosis in first 4- to 24-hour period.

- In vasopressin vs norepinephrine trial ( $n=778$, multicenter, double-blind, parallel group, randomized controlled trial), less serious septic shock was reported with vasopressin $(p=0.05)$, but otherwise no significant difference was found. ${ }^{17}$

- Meta-analysis of the vasopressin/terlipressin treatment in vasodilatory shock did not exhibit any significant survival benefit. ${ }^{18}$ However, the use of vasopressin or terlipressin, although not showing any survival benefit, may be valued by physicians due to sparing effects on norepinephrine requirement.

\section{Newer Agents for Refractory Vasodilatory Shock}

Refractory vasodilatory shock is defined as hypotension despite the use of high doses of vasopressors. It is a very critical condition, where 30-day all-cause mortality in treatment-refractory septic shock is more than $50 \%$.

In a very first trial using angiotensin, blood pressure was normalized in 15 out of 21 critically ill patients. ${ }^{19}$ Then, comes the Angiotensin II for the Treatment of High-Output Shock (ATHOS) trial, a pilot study $(n=20)$ that showed human angiotensin II can effectively increase MAP. ${ }^{20}$ Subsequently, a larger ATHOS 3 trial ( $n=$ 344) conducted over 75 ICUs showed that Angiotensin II effectively increased blood pressure in patients with vasodilatory shock, who did not respond to high doses of conventional vasopressors. ${ }^{21}$ As a sequel to the above-mentioned trial, US-FDA finally approved Giapreza (angiotensin II) in December 2017 as an intravenous infusion to increase blood pressure in adults with septic or other distributive shock. ${ }^{22}$

Two other drugs are still evolving: vasopressin and selepressin (V1a selective agonist), which are under active trials. The use of selepressin $2.5 \mathrm{ng} / \mathrm{kg} / \mathrm{min}$ infusion in early septic shock ( $n=53$, multicentre, double-blind, parellel group, placebo-controlled trial) showed higher proportion of patient maintaining MAP without norepinephrine with less mean cumulative dose of norepinephrine as well as shorter duration of shock with mortality benefits. ${ }^{23}$

\section{Extracorporeal Membrane Oxygenation}

In recent years, positive experiences using extracorporeal membrane oxygenation (ECMO) as respiratory support with a venovenous cannulation strategy (VV ECMO) and as cardiac/ cardiorespiratory support with a venoarterial strategy (VA ECMO) have been reported. ${ }^{18,19}$ The application of ECMO may optimize tissue perfusion, allowing a "metabolic rest" by reducing the need for a pressor and inotropic drugs and enabling the use of less aggressive ventilatory support. Recent retrospective studies have offered some insights regarding the use of ECMO in adult patients with refractory septic shock. ${ }^{24-26}$ Taken together, the above-mentioned studies clarified that ECMO appears to achieve worse results with a pattern of distributive shock with high cardiac output and low SVR. In contrast, the use of VV ECMO in the early stages of hemodynamic compromise could well be rationalized attributed to its role in the correction of hypoxemia, acidosis, and pulmonary hyperinflation.

Extracorporeal blood purification therapies have been proposed to improve the outcome for patients with severe sepsis with and without acute kidney injury. ${ }^{27,28}$ The underlying principle is the removal of excessive inflammatory mediators and/ or bacterial toxins from the blood compartment to modulate the inflammatory response. This involves various techniques, including hemoperfusion/hemadsorption, high-adsorption hemofiltration, high-volume hemofiltration (HVHF), high cutoff (HCO) membrane hemofiltration/hemodialysis, plasma exchange, and coupled plasma filtration adsorption (CPFA).

The rational for the above-mentioned approach is to achieve "immune homeostasis," which counteracts the immune dysregulation of the host response to infection. With the role of various cytokines established in sepsis, it is assumed that to get rid of such substances could ameliorate the deteriorating consequences in the early phase of sepsis. ${ }^{29}$ Despite early promise, no multicenter RCT has shown a survival benefit with the use of the HVHF technique. ${ }^{30,31}$ Similarly, a meta-analysis depicting a role of the extracorporeal blood purification technique also failed to demonstrate survival benefit. ${ }^{32}$ This might be attributed to the variation in different factors, such as intensity of cytokine production, the number of receptors, clearance of such mediators, and affinity of receptors for such mediators. The enhanced inflammatory response could well be linked with the production of pro- and anti-inflammatory mediators rather than the disequilibrium in between. ${ }^{29}$ Therefore, a similar technique, such as continuous venovenous hemofiltration (CVVH), has not really appreciated any clinical benefit. ${ }^{33}$ However, meta-analysis suggested that the only potential effective blood purification technique for the sepsis is plasma exchange or hemadsorption with polymyxin $\mathrm{B}^{34}$

A recent $R C T$ involving 20 patients being administered hemadsorption therapy (CytoSorb) as a stand-alone therapy within first 24 hours of onset of septic shock shown to be safe and resulted in a significant reduction in norepinephrine requirements in the CytoSorb group compared with the control. ${ }^{35}$ The largest study that follows an open-label RCT done in 10 German study sites involving a total of 582 patients with 100 mechanically ventilated patients with severe sepsis or septic shock together with acute lung injury or acute respiratory distress syndrome, to be recruited. CytoSorb was administered for 6 hours per day for 7 days. Compared with the standard care, the application of this technique has not shown any significant overall reduction of the IL- 6 level in blood compared with the control. Moreover, there was no association between treatment with hemadsorption and mortality or any secondary endpoints, such as duration of mechanical ventilation or MOD score. ${ }^{36}$ On the contrary, various case series in patients with sepsis do point to a reduction in vasopressor dose. ${ }^{37}$ The third interim analysis of 135 patients in Acute Physiology and Chronic Health Evaluation II (APACHE-II) trial demonstrated mortality of $65 \%$ against the predicted mortality of $78 \%$ in patients with APACHE-II score $>25$. $^{38}$ 
The key takeaway message from the above-mentioned trials corroborate the fact that the initiation of early therapy in vasodilatory shock can impose maximized benefits. However, timing to intervention must be adjusted with characterization and onset of immunosuppression. Various pharmacokinetic studies on cytokine clearance would be extremely useful to delineate the therapy duration. As evident from the APACHE-II study, the effect of intervention might vary ascribed to the disease severity. More robust well-conducted randomized controlled studies with the selection of appropriate patients and endpoints of physiological relevance can be conducive for betterment of future knowledge regarding these techniques.

\section{Conclusion}

Vasodilatory shock is a leading cause of death in ICU setups, and its most common form is septic shock. Other than definitive therapy, fluid therapy and vasoactive medications are the most important supporting care to increase survival benefits. Despite optimal treatment with well-defined protocols, mortality rate remains high. Other promising interventions promulgated via clinical trials might pave the way toward more robust as well as practical treatment protocol. There should be more focused way of acquiring better knowledge through the adoption of scientifically sound as well as clinically pertinent research protocol.

\section{References}

1. Vincent JL, De Backer D. Circulatory shock. N Engl J Med 2013;369:1726-1734.

2. Hershey TB, Kahn JM. State sepsis mandates - A new era for regulation of hospital quality. N Engl J Med. 2017;376:2311-2313.

3. The death toll of sepsis in India [Internet]. Health Issues India. Available at https://www.healthissuesindia.com/2018/09/13/thedeath-toll-of-sepsis-in-india/ [Last retrieved September 17, 2019].

4. Divatia JV, Amin PR, Ramakrishnan N, Kapadia FN, Todi S, Sahu S, et al. Intensive care in India: The Indian intensive care case mix and practice patterns study. Indian J Crit Care Med. 2016;20:216-225.

5. Schultz MJ, Dunser MW, Dondorp AM, Adhikari NK, lyer S, Kwizera $A$, et al. Current challenges in the management of sepsis in ICUs in resource-poor settings and suggestions for the future. Intensive Care Med. 2017;43:612-624.

6. Landry DW, Oliver JA. The pathogenesis of vasodilatory shock. N Engl J Med. 2001;345:588-595.

7. Haseer Koya H, Paul M. Shock. [Updated 2018 Oct 27]. In: StatPearls [Internet]. Treasure Island: StatPearls Publishing; 2019 Jan. Available at: https://www.ncbi.nlm.nih.gov/books/NBK531492/[Last retrieved September 17, 2019]

8. Bednarczyk JM, Fridfinnson JA, Kumar A, Blanchard L, Rabbani R, Bell $D$, et al. Incorporating dynamic assessment of fluid responsiveness into goal-directed therapy. Crit Care Med. 2017;45:1538-1545.

9. Rhodes A, Evans LE, Alhazzani W, Levy MM, Antonelli M, Ferrer R, et al. Surviving Sepsis Campaign: International guidelines for management of sepsis and septic shock. Intensive Care Med. 2017;43:304-377.

10. Levy MM, Evans LE, Rhodes A. The Surviving Sepsis Campaign Bundle: 2018 update. Intensive Care Med. 2018;44:925-928.

11. Moeller C, Fleischmann C, Thomas-Rueddel D, Vlasakov V, Rochwerg $\mathrm{B}$, Theurer $\mathrm{P}$, et al. How safe is gelatin? A systematic review and metaanalysis of gelatin-containing plasma expanders vs crystalloids and albumin. J Crit Care. 2016;35:75-83.

12. Finfer S, Bellomo R, Boyce N, French J, Myburgh J, Norton R. A comparison of albumin and saline for fluid resuscitation in the intensive care unit. N Engl J Med. 2004;350:2247-2256.

13. Aironi P, Tognoni G, Masson S, Fumagalli R, Pesenti A, Romero M, et al. Albumin replacement in patients with severe sepsis or septic shock. N Engl J Med. 2014;370:1412-1421.
14. De Backer D, Biston P, Devriendt J, Madl C, Chochrad D, Aldecoa C, et al. Comparison of dopamine and norepinephrine in the treatment of shock. N Engl J Med. 2010;362:779-789.

15. Avni T, Lador A, Lev S, Leibovici L, Paul M, Grossman A. Vasopressors for the treatment of septic shock: Systematic review and metaanalysis. PLoS One. 2015;10(8):e0129305.

16. Myburgh JA, Higgins A, Jovanovska A, Lipman J, Ramakrishnan N, Santamaria J, et al. A comparison of epinephrine and norepinephrine in critically ill patients. Intensive Care Med. 2008;34:2226-2234.

17. Russell JA, Walley KR, Singer J, Gordon AC, Hébert PC, Cooper DJ, et al. Vasopressin versus norepinephrine infusion in patients with septic shock. N Engl J Med. 2008;358:877-887.

18. Polito A, Parisini E, Ricci Z, Picardo S, Annane D. Vasopressin for treatment of vasodilatory shock: An ESICM systematic review and meta-analysis. Intensive Care Med.2012;38:9-19.

19. del Greco F, Johnson DC. Clinical experience with angiotensin II in the treatment of shock. JAMA.1961;178:994-996.

20. Chawla LS, Busse L, Brasha-Mitchell E, Davison D, Honiq J, Alotaibi Z, et al. Intravenous Angiotensin II for the Treatment of High-Output Shock (ATHOS trial): A pilot study. Crit Care. 2014;18:534.

21. Chawla LS, Russell JA, Bagshaw SM, Shaw AD, Goldstein SL, Fink MP, et al. Angiotensin II for the Treatment of High-Output Shock 3 (ATHOS3): Protocol for a phase III, double-blind, randomised controlled trial. Crit Care Resusc. 2017;19:43-49.

22. FDA approves drug to treat dangerously low blood pressure: FDA news release 2017 [Internet]. US Food and Drug Administration. Available at https://www.fda.gov/news-events/press-announcements/ fda-approves-drug-treat-dangerously-low-blood-pressure [Last retrieved September 19, 2019].

23. Russell JA, Vincent J-L, Kjølbye AL, Olsson H, Blemings A, Spapen $H$, et al. Selepressin, a novel selective vasopressin V1A agonist, is an effective substitute for norepinephrine in a phase lla randomized, placebo-controlled trial in septic shock patients. Crit Care. 2017;21(1):213.

24. Park TK, Yang JH, Jeon K, Choi SH, Choi JH, Gwon HC, et al. Extracorporeal membrane oxygenation for refractory septic shock in adults. Eur J Cardiothorac Surg. 2015;47:e68-e74.

25. Von Bahr V, Hultman J, Eksborg S, Frenckner B, Kalzen H. Longterm survival in adults treated with extracorporeal membrane oxygenation for respiratory failure and sepsis. Crit Care Med. 2017;45:164-170.

26. Cheng A, Sun HY, Lee CW, Ko WJ, Tsai PR, Chuang YC, et al. Survival of septic adults compared with nonseptic adults receiving extracorporeal membraneoxygenation for cardiopulmonary failure: A propensity-matched analysis. J Crit Care. 2013;28:532.

27. Cole L, Bellomo R, Hart G, Journois D, Davenport P, Tipping P, et al. A phase II randomized, controlled trial of continuous hemofiltration in sepsis. Crit Care Med 2002;30:100-106.

28. Payen D, Mateo J, Cavaillon JM, Fraisse F, Floriot C, Vicaut E, et al. Impact of continuous venovenous hemofiltration on organ failure during the early phase of severe sepsis: A randomized controlled trial. Crit Care Med 2009;37:803-810.

29. Lukaszewicz AC, Payen D. Purification methods: A way to treat severe acute inflammation related to sepsis? Crit Care. 2013;17:159.

30. Cole L, Bellomo R, Journois D, Davenport P, Baldwin I, Tipping P. Highvolume haemofiltration in human septic shock. Intensive Care Med. 2001;27:978-986.

31. Joannes-Boyau O, Honoré PM, Perez P, Bagshaw SM, Grand H, Canivet $\mathrm{JL}$, et al. High-volume versus standard-volume haemofiltration for septic shock patients with acute kidney injury (IVOIRE study): A multicentre randomized controlled trial. Intensive Care Med. 2013;39:1535-1546.

32. Clark E, Molnar AO, Joannes-Boyau O, Honoré PM, Sikora L, Bagshaw SM. High-volume hemofiltration for septic acute kidney injury: A systematic review and meta-analysis. Crit Care. 2014;18:R7.

33. De Vriese AS, Colardyn FA, Philippé JJ, Vanholder RC, De Sutter JH, Lameire NH. Cytokine removal during continuous hemofiltration in septic patients. J Am Soc Nephrol. 1999;10:846-853. 
34. Chang T, Tu YK, Lee CT, Chao A, Huang CH, Wang MJ, et al. Effects of polymyxin $B$ hemoperfusion on mortality in patients with severe sepsis and septic shock: A systemic review, meta-analysis update, and disease severity subgroup meta-analysis. Crit Care Med. 2017;45(8):e858-e864.

35. Hawchar F, László I, Öveges N, Trásy D, Ondrik Z, Molnar Z. Extracorporeal cytokine adsorption in septic shock: A proof of concept randomized, controlled pilot study. J Crit Care. 2019;49:172-178.

36. Schädler D, Pausch C, Heise D, Meier-Hellmann A, Brederlau J, Weiler $\mathrm{N}$, et al. The effect of a novel extracorporeal cytokine hemoadsorption device on IL-6 elimination in septic patients: A randomized controlled trial. PLoS One. 2017;12:e0187015.

37. Matson J, Zydney A, Honoré PM. Blood filtration: New opportunities and the implications of systems biology. Crit Care Resusc. 2004;6:209217.

38. Friesecke S, Träger K, Schittek GA, Molnar Z, Bach F, Kogelmann K, et al. International registry on the use of the CytoSorb ${ }^{\circledast}$ adsorber in ICU patients: Study protocol and preliminary results. Med Klin Intensivmed Notfmed. 2017. doi: 10.1007/s00063-017-0342-5. [Epub ahead of print] Review. 